\title{
Digital Inventory and Documentation of Korea's Important Cultural Properties Using 3D Laser Scanning
}

\author{
Kang Dongseok ${ }^{a}, * \operatorname{Kim}_{\text {Gyesoo }}{ }^{\mathrm{b}}$, Kim Siro $^{c}$, Kim Eunhwa $^{\mathrm{d}}{ }^{*}$ \\ ${ }^{a, b}$ Cultual Heritage Administration, 189 Cheongsa-ro, Seo-gu, Daejeon, Korea \\ - (kydhsh1214@gmail.com, girogi@korea.kr) \\ c, d Heritage Digital Archive Center, Jeongjadong, Bundang-gu, Seongnam-si, Gyeonggi-do, Korea \\ - (siro7575@gmail.com, kimura1919@naver.com)
}

\begin{abstract}
:
As a country with 11 properties included on the World Heritage List and approximately 12,000 important cultural properties, Korea has been continuously carrying out the inventory and documentation of cultural properties to conserve and manage them since the 1960s. The inventory of cultural properties had been carried out by making and managing a register which recorded basic information mainly on state-designated cultural properties such as their size, quantity, and location. The documentation of cultural properties was also carried out by making measured drawings. However, the inventory and documentation done under the previous analog method had a limit to the information it could provide for the effective conservation and management of cultural properties. Moreover, in recent times important cultural properties have frequently been damaged by man-made and natural disasters such as arson, forest fires, and floods, so an alternative was required.

Accordingly, Korea actively introduced digital techniques led by the government for the inventory and documentation of important cultural properties. In this process, the government established the concept of a digital set, built a more efficient integrated data management system, and created standardized guidelines to maximize the effectiveness of data acquisition, management, and utilization that greatly increased the level of digital inventory, documentation, and archiving.
\end{abstract}

Keywords: Important cultural properties, man-made and natural disasters, cultural properties conservation, digital documentation, data standard, 3D laser scanning

\section{INTRODUCTION}

The central and local governments divide up the conservation and management of Korea's important cultural properties. The central government, along with cities and provinces, each designate and manage the state-designated and city and province-designated cultural properties in accordance with the cultural property designation rule. In particular, national important cultural properties are divided into national treasures, treasures, important intangible cultural properties, historic sites, scenic sites, natural monuments, and others, and managed based on their historical, artistic, academic, and scenic value among the tangible and intangible cultural properties, which can be evaluated as the national, ethnical, and global heritage. As of March 2015, there were a total of 3,603 state-designated cultural properties in Korea. Approximately 12,000 cultural properties are administratively managed including the cultural properties managed by local governments.

In regard to such state-designated cultural properties, the Cultural Heritage Administration, a national administrative agency, has directly conserved and managed important cultural properties since the $1950 \mathrm{~s}$. It also carried out the conservation and management of important cultural properties in various ways, not only directly repairing and restoring, and financially supporting tangible and intangible cultural properties, but also in the inventory and documentation of the survey records, drawings, photographs, videos and other items relating to important cultural properties. In this process, however, events happened after the mid-2000s which drastically changed the method, contents, and standard of the inventory and documentation of such important cultural properties.

The first event was the Sungnyemun Gate incident when a fire destroyed National Treasure No. 1 in 2008. Korea's symbolic gate tower was destroyed in a fire. As the 3D laser scanning data, which was acquired before the fire, was used during the process of its restoration, the importance of the digital record acquisition and management of tangible cultural properties including wooden cultural properties came to the fore. Moreover, the need for a project to digitally document the archetypical information of important cultural properties in case of various natural disasters such as arson, forest fires and floods was raised. It also served as an opportunity to change the direction of the inventory and documentation of important cultural properties towards digital-based records.

Meanwhile, as digital technology became more common in society as a whole from 2010, social demands on opening, sharing, and utilizing the information on important cultural properties have increased. As effective ways for dealing with such demands, the 3D laser scanning techniques were actively

\footnotetext{
* Corresponding author
} 
introduced and applied to the inventory and documentation of important cultural properties.

The inventory and documentation of the 3D digital information on Korea's important cultural properties were introduced for the purpose of managing archetypical information and utilizing information resources. During this process, digital inventory and documentation were actively carried out by each cultural property management sector within the Cultural Heritage Administration. However, establishing a data organization system, improving the project implementation system, acquiring and managing the data, and standardizing the quality were necessary for the promotion of a more efficient project and the integrated management and securing of higher quality data. It was linked with the 'digital set construction project of the records information resources for the cultural heritage,' which was carried out by the Cultural Heritage Administration. Moreover, projects became successful through the reviewing, improving, and standardization of the existing method for the inventory and documentation of the $3 \mathrm{D}$ digital archetypical information, which was one of the weakest sectors in the composition of the digital set. This study introduces the process of problem solving and results regarding the problems that occurred during the inventory and documentation process using 3D laser scanning, and detailed examples.

\section{CURRENT STATE AND PROBLEMS}

\subsection{Current state}

Since the mid-2000s, the importance of acquiring, managing, and utilizing the digital information of important cultural properties has been growing, not only in the Cultural Heritage Administration, an administrative agency which directly manages cultural properties, but also across Korean society. Accordingly, the state-led organization and supplementation of the previously established digital data and the acquisition of new data were actively progressed under the Cultural Heritage Administration for the inventory and documentation of important cultural properties. It primarily aimed to utilize them as basic resources which conserve the archetypes in case of important cultural properties being damaged by a man-made or natural disaster such as arson, forest fires, and floods. Secondarily, it aimed to establish research studies, an information service, and application content using the acquired digital information.

In regard to the method of implementing the project, specialist divisions, which were in charge of the conservation and management of movable properties, buildings, historical sites, archaeological data, and others within the Cultural Heritage Administration, carried out the project as an individual project unit. For the major digital technologies, technologies to establish a spatial database on important immovable cultural properties and archaeological data by utilizing a geographic information system (GIS), and to acquire the digital archetypical information using 3D laser scanning were introduced.

The cultural property geographic information system is a work designed to digitally inventory national treasures, treasures, historical sites, archaeological data, and others across the country which have locational information. The work is carried out by establishing the spatial database and providing a map service from the established data. As a result, a digital inventory of spatial information which includes locational information of state-designated important immovable cultural properties all over the country and archaeological data was achieved, and it contributed greatly not only to the basic conservation and management of cultural properties, but also to the utilization of the data.

Meanwhile, 3D laser scanning, which was used in various fields in the early 1990s such as in the measurement of archaeological sites, the precision measurement and safety inspection of wooden cultural properties, and the reproduction of national treasures and treasures, began with the digital measurement of important movable cultural properties. In particular, 3D laser scanning of the archaeological sites was highly used because it had been evaluated as a revolutionary technology which could permanently preserve the archetypical information of cultural properties that were certain to be demolished due to construction work. Moreover, as 3D laser scanning was able to measure digitally, which could secure a high degree of precision, it was actively introduced in the outdoor measurement of excavated remains such as old tombs and building remains. It was also frequently used in the measurement of relics. The usefulness of 3D laser scanning was recognized at the conservation management sites of wooden cultural properties, therefore it has become more common. The precision measurement of wooden cultural properties using 3D laser scanning is recognized as an advanced technical skill which can secure high precision, as high as that by existing manual measurements, and supplement the limitations such as long working hours. In particular, 3D laser scanning is effectively used for the safety inspection of wooden cultural properties which could suffer from tilting, warping, and other structural problems. Besides, in the movable cultural property fields, 3D laser scanning is actively used to allow the observation of the detailed patterns on pottery and porcelain, the interpretation of tombstone inscriptions, and the reproduction and restoration of relics. Projects are mainly carried out on Buddhist bells, statues of the Buddha, and stone pagodas.

The 3D laser scanning is used in various fields such as digital inventory and documentation, precision measurement, safety inspections, research studies, reproduction and restoration, and content production of important cultural properties.

\subsection{Problems}

As examined above, 3D laser scanning is applied very widely in the fields of conservation, management, and utilization of Korea's important cultural properties. Therefore, the digital inventory and documentation, in terms of the conservation of the archetypical information and information utilization, can be said to be the most important and basic process. In this way, 3D laser scanning has been actively introduced and utilized in the conservation and management fields of cultural properties. However, the digital inventory was carried out by individual subject units and the distinct characteristics of each field of cultural properties were overemphasized. Therefore, it had problems with the general management and future utilization of the end products of the inventory projects. In particular, integrated management of the inventory and documentation projects of important cultural properties, establishment of a data system, methods for the 
acquisition and management of data, and reorganization for quality standardization were required.

First, the need for integrated management of the digital inventory and documentation projects which were carried out diversely in many fields was raised. Integrated management of the contents and results of the projects, and the supplementation of infrastructure for the acquisition, management, and utilization of data were needed to carry out projects consistently. To solve these problems, there was a need to form a basic system for digital inventory, to establish a medium to long-term master plan, and to build an integrated management system for the project. The state-led digital inventory was required to establish a plan for the inventory and documentation of important cultural properties in their entirety and to reorganize the integrated management of the generated data and the role of each project entity's system rather than the existing process by project unit. In order to solve such limitations and problems, the system has been organized to manage and utilize data more effectively by redesigning the work system of the digital inventory and documentation project entity by 3D laser scanning.

Second, a data set which could be used in the digital database management system for all important cultural properties rather than management of the digital information resources being limited to $3 \mathrm{D}$ laser scanning needed to be formed. In fact, this can be considered as the most important process in the way that it organized the system on the entire digital inventory of cultural properties. The digital inventory process by $3 \mathrm{D}$ laser scanning was the concept included in the organization system of this data set so that it formed one list out of the various digital lists on unit cultural properties. The organization system of this data set was organized as a concept of the 'cultural heritage digital set,' and greatly contributed to the process of the inventory and documentation of cultural properties.

Third, it requires reorganizing the standardization of the cultural property inventory work process, data quality, and outputs using 3D laser scanning. Meanwhile, laser scanning, which formed a large part of the inventory and documentation of the important cultural properties, had complicated procedural problems such as with data acquisition, the process, and non-standardization of data without taking into account the type and characteristics of a cultural property. New guidelines were required to be set out to solve these problems. This was carried out as part of the 'cultural heritage digital set 3D database construction project,' which was carried out by the Cultural Heritage Administration of Korea from 2011. As a result, new guidelines have been completed, and are used in each project field.

\section{CONSTRUCTION OF AN INTEGRATED MANAGEMENT SYSTEM THROUGH REENGINEERING THE BUSINESS PROCESS}

The inventory of cultural properties using 3D laser scanning in Korea was led by the state, and carried out in the form of a medium to long-term project by each cultural property management division such as historic sites, movable properties, and archaeological sites. However, such 3D digital inventory data was produced, managed, and utilized ineffectively due to the absence of an integrated data management system. For the purpose of overcoming the limitations, 'Guidelines for the
Management and Utilization of Cultural Property Documentation Projects' were established, and the business process was reengineered as below, to build an efficient and systematic data management system.

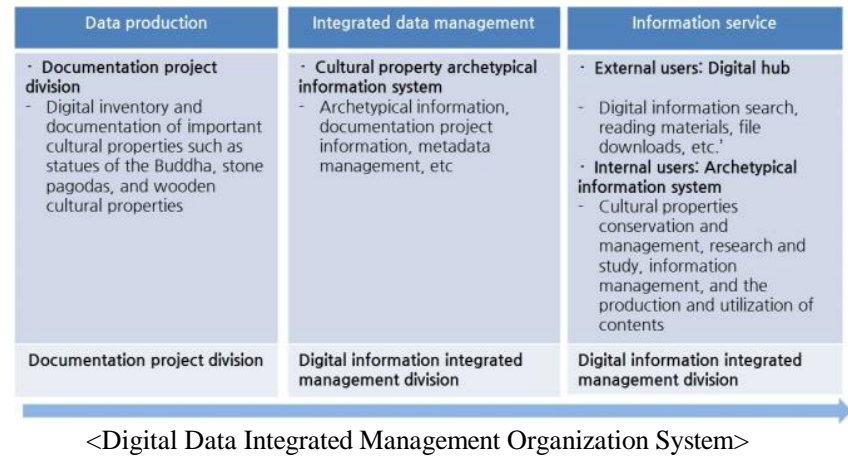

Such a work process is composed of a system where each division in the Cultural Heritage Administration, which manages important cultural properties such as national treasures and treasures, and produces digital resources, and then a division in charge of the informatization of cultural properties, builds and operates an information system which can collectively manage and utilize the data using these resources and collectively manages them. This work process has established a foundation on which to progress the digital inventory more systematically, and to construct infrastructure which enables digital resources to be managed and utilized more effectively and efficiently. It helps in solving problems of not managing the 3D laser scanning efficiently due to a lack of storage management infrastructure in each division, although a large amount of 3D laser scanning was acquired as the outcome of digital inventory and documentation projects. Moreover, as the digital data of all public institutions has been open to the public since 2014, a system which can utilize the data acquired through 3D laser scanning more efficiently within the integrated management system was employed.

Meanwhile, as the overall progress of the digital inventory and documentation projects can be checked due to such business process reengineering, projects can be arranged so that they do not overlap. As managing divisions that can collectively manage projects have been designated, a medium to long-term master plan for the related projects has been established. The 'Cultural Heritage Digital Set 3D Database Construction Project' has been carried out since 2011 according to the established master plan. This plan supplements the existing digital inventory and documentation projects that had concentrated on particular cultural properties. It provides an opportunity to increase the effectualness of projects by maintaining the basis of digital inventory and documentation projects on existing movable cultural properties and architectural cultural properties, while preferentially selecting those cultural properties which are not included in a project but urgently need digital inventory and documentation. It enables a plan to be completed for the digital inventory and documentation of all the important cultural properties.

At present, targets for the inventory and documentation of cultural properties using 3D laser scanning by the Cultural Heritage Administration of Korea are as follows. A total of 72 cases of the digital inventory had been completed until 2014, and it aims to complete 1,088 cases of the digital inventory on important cultural properties over the next five years. 


\begin{tabular}{c|c|c|c|c|c|c}
\hline Classification & $\mathbf{2 0 1 5}$ & $\mathbf{2 0 1 6}$ & $\mathbf{2 0 1 7}$ & $\mathbf{2 0 1 8}$ & $\mathbf{2 0 1 9}$ & Subtotal \\
\hline National Treasures & 10 & 8 & & & & 18 \\
\hline Treasures & 10 & 64 & 89 & 112 & 135 & 410 \\
\hline Natural Monuments & & 3 & 20 & 10 & & 33 \\
\hline $\begin{array}{c}\text { Important Folklore } \\
\text { Cultural Properties }\end{array}$ & 28 & 28 & 53 & 67 & 176 \\
\hline $\begin{array}{c}\text { Registered Cultural } \\
\text { Properties and } \\
\text { others }\end{array}$ & 92 & 106 & 116 & 137 & 451 \\
\hline Subtotal & $\mathbf{2 0}$ & $\mathbf{1 9 5}$ & $\mathbf{2 4 3}$ & $\mathbf{2 9 1}$ & $\mathbf{3 3 9}$ & $\mathbf{1 , 0 8 8}$ \\
\hline
\end{tabular}

\section{COMPOSITION OF THE CULTURAL HERITAGE DIGITAL SET}

The records information resources from the digital inventory and documentation of Korea's important cultural properties where an independent system was formed which carried out the production, management, and service of information by a system with competent institutions had its limitations. This led to the dispersion and overlapping of the cultural heritage information so that the data existed in a fragmented form.

The concept of the 'cultural heritage digital set' was introduced to solve these problems. The cultural heritage digital information which was dispersed in a system by each institution was composited into a set. This had the effect of increasing the conservation and management work efficiency using the cultural heritage digital information, and providing the best service which met the demands of various users such as general users, professional users, content producers, and others who wanted to use the cultural heritage digital information.

The basic concept of the 'cultural heritage digital set' is to establish a data set by dividing each important cultural property into one of the areas of basic resources, historical resources, and analytical resources. The detailed definitions are as follows.

Basic resources: Core resources that can directly reproduce a cultural property.

Historical resources: Information resources that can provide the history of a cultural property and its management context.

Analytical resources: Academic, research, and study records for each cultural property.

The digital set of the important cultural properties can be regarded as a complex of various contents. The most essential element among them is the basic resources such as photographs and drawings. Various hardware and software such as GPS, $\mathrm{CAD}$, GIS, and lidar are used for the acquisition and management of such basic resources. The most representative among them is three-dimensional archetypical information taken using 3D laser scanning. During the work process, 3D laser scanning is carried out in a combination of taking digital measurements, survey, photography, securing spatial data, and producing maps and drawings on the cultural properties. Therefore, a database construction project using a laser scanner can be considered a very important project in terms of securing the basic resources for digital inventory and documentation.

As the 'cultural heritage data set' organization system was completed and the 3D laser scanning data, which was carried out fragmentarily during the inventory or measurement process so far, was categorized as a basic resource, not only the management of data but also the securing of high quality data became more important. As a digital system, which was a base for systematically progressing the digital inventory through $3 \mathrm{D}$ laser scanning, was established, the importance of the standardization of the work process and data were emphasized.

\section{STANDARDIZATION OF DIGITAL INVENTORY AND DOCUMENTATION OF IMPORTANT CULTURAL PROPERTIES USING 3D LASER SCANNING}

Laser scanning is the most commonly used method for the inventory and documentation of Korea's important cultural properties, and produces the major data which forms the inventory of important cultural properties. However, the management and utilization of laser scanning was in a fragile state due to reckless progress without regard for guaranteeing the quality of the data and non-standardization of data. To compensate for these problems, standardization guidelines on the work procedures and data have been created, and applied on the actual work field.

The results are the 'Guidelines of 3D Laser Scanning for Cultural Properties.' Since the digital inventory and documentation using 3D laser scanning were actively progressed, it aimed to lay out the guidelines for the acquisition, management, and utilization of data for the future. For the production process of the guidelines, first, case studies were carried out to decide on an appropriate scanning method on a particular cultural property by scanning according to type, size, and texture. With the result, the work procedure, composition of data, and quality standard were laid out to increase the degree of completion of the digital inventory and documentation for each cultural property.

\subsection{Standardization of work procedure}

For the work procedure, the purpose of the digital inventory and documentation of cultural properties, and characteristics of the objects were fully grasped to decide on the scanning method, and then the digital inventory was carried out according to the procedure, an image set out below, for carrying out the main survey, the post-processing of data, and producing outputs.

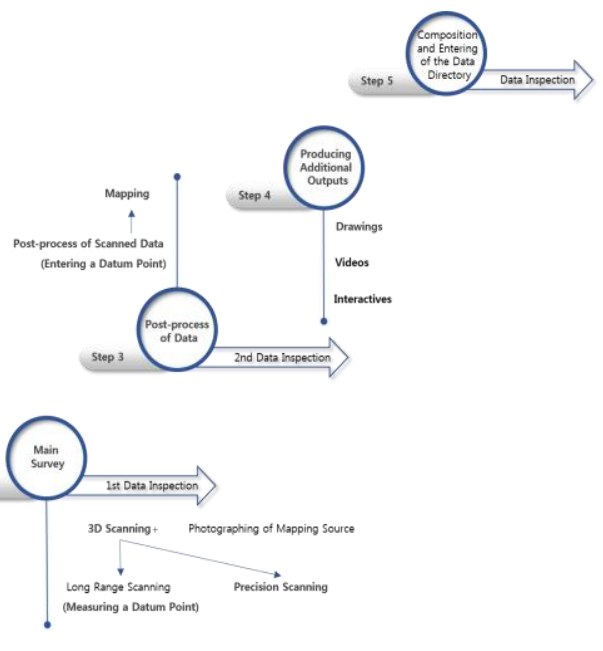

<Procedure for the Digital Inventory Using Laser Scanning> 
Looking at the details of the standardization of work procedure concretely, first, the step to determining a scanning method refers to the process of deciding on a scanning method through a pilot study and environmental analysis on the target cultural property prior to undertaking the inventory work using 3D laser scanning, and establishing a detailed work plan. In regard to the scanning methods, the specifications of the scanner were determined according to the total size, complexity of the shape, details of carving, accessibility, glossiness, and surface color. As selecting the minimum point density required the acquisition of the figure and characteristics of the target cultural property as point cloud data, this was a primary element in deciding the scanning methods. Above all, the analysis of the characteristics of the target cultural property and the purpose and nature of the project took precedence. In addition, limited space for scanning, surface glossiness, and surface color were considered secondary factors for selecting the scanning method and equipment. To select a scanning method according to the characteristics of a cultural property and scanning environment based on such criteria, the criteria was established as shown in the tables below.

\begin{tabular}{|c|c|c|c|}
\hline $\begin{array}{c}\text { Characteristics of the Cultural } \\
\text { Properties }\end{array}$ & Examples of Cultural Properties & \begin{tabular}{|c|} 
Point \\
Density \\
\end{tabular} & $\begin{array}{l}\text { Scanning } \\
\text { Method }\end{array}$ \\
\hline $\begin{array}{l}\text { A cultural property that is } \\
\text { formed with many cultural } \\
\text { properties inside }\end{array}$ & is Palaces, fortresses, temples & \multirow{3}{*}{$\begin{array}{c}3 \mathrm{~mm} \sim \\
10 \mathrm{~mm}\end{array}$} & \multirow{3}{*}{$\begin{array}{l}\text { Long Range } \\
\text { Scanning }\end{array}$} \\
\hline Buildings and constructions & $\begin{array}{|lc|}\begin{array}{l}\text { Architectural cultural properties, } \\
\text { pagodas, stone monuments }\end{array} & \\
\end{array}$ & & \\
\hline Archaeological sites & The sites of kilns and temples & & \\
\hline $\begin{array}{lll}\begin{array}{l}\text { Shallow and } \\
\text { engravings }\end{array} & \text { elaborate } \\
\end{array}$ & $\begin{array}{l}\text { Sculptures, craftwork, an image of the } \\
\text { Buddha carved on a natural rock-wall, } \\
\text { engraved images on a rock }\end{array}$ & \multirow{2}{*}{$\begin{array}{c}1 \mathrm{~mm} \sim \\
3 \mathrm{~mm}\end{array}$} & \multirow{2}{*}{$\begin{array}{l}\text { Precision } \\
\text { Scanning }\end{array}$} \\
\hline $\begin{array}{l}\text { Parts of architectural cultural } \\
\text { properties }\end{array}$ & $\begin{array}{l}\text { anopies, rotating sutra columns, eave } \\
\text { decorations, bridge, stone figures }\end{array}$ & & \\
\hline $\begin{array}{l}\text { Small sculptures and badly } \\
\text { worn out sculptures }\end{array}$ & $\begin{array}{l}\text { y Small gilt bronze Buddhist statues, } \\
\text { bronze mirrors, bronze seals }\end{array}$ & \multirow{2}{*}{$\begin{array}{l}\text { Less than } \\
1 \mathrm{~mm}\end{array}$} & \multirow[b]{2}{*}{$\begin{array}{l}\text { Precision } \\
\text { Scanning }\end{array}$} \\
\hline $\begin{array}{l}\begin{array}{l}\text { Cultural properties } \\
\text { shallow andaining } \\
\text { engravings }\end{array} \\
\text { elaborate }\end{array}$ & $\begin{array}{l}\text { gThe woodblocks of the Tripitaka, } \\
\text { ewooden Triptych Buddhist statue, } \\
\text { bronze mirror }\end{array}$ & & \\
\hline
\end{tabular}

\begin{tabular}{|c|c|c|}
\hline $\begin{array}{c}\text { Characteristics of the } \\
\text { Scanning Environment }\end{array}$ & Examples of Cultural Properties & Scanning Method \\
\hline $\begin{array}{l}\text { In the case of limite } \\
\text { working space }\end{array}$ & $\begin{array}{l}\text { The interior of large statues of the } \\
\text { Buddha }\end{array}$ & $\begin{array}{l}\text { Utilizing 3D multi-imaging } \\
\text { photography equipment }\end{array}$ \\
\hline $\begin{array}{l}\text { In the case of very gloss } \\
\text { objects }\end{array}$ & $\begin{array}{l}\text { Gilt bronze Buddhist statues, } \\
\text { Goryeo celadons, metal cultural } \\
\text { properties }\end{array}$ & 3D multi-imaging photography \\
\hline $\begin{array}{l}\text { In the case of the surfac } \\
\text { being close to black in color }\end{array}$ & $\begin{array}{l}\text { Woodblocks of the Buddhist } \\
\text { scriptures }\end{array}$ & \\
\hline
\end{tabular}

Meanwhile, the main survey, which is carried out after the selection of the scanning method, refers to the work procedure where scanning data is acquired on the site of the target property. As an example of a long range scan, data is acquired through 3D scanning and mapping source photography according to the work plan established during the step to decide on a scanning method. After the acquired data has gone through post-processing at each step, location data is assigned by entering a datum point. Mapping is carried out in color, and then the scanning process is completed.

In the past, there were many cases where the measurement of a datum point by GPS was omitted when scanning cultural properties using long range scanners. However, immovable cultural properties must have location information. Scanned points have the X-, Y-, and Z-coordinates located in the space, therefore measurements need to accompany it. The utilization of scanning data in the spatial information system such as GIS has increased recently, so the acquisition of absolute coordinates has become more important. When a datum point measurement on important cultural properties was required, the location standards concerning spatial information such as the coordinate system of the scanned area and measured datum point were confirmed, and scanning was carried out at the measured datum point.

As items requiring caution in the main survey, in the case of a cultural property with many framework materials and a complex structure, scanning was carried out repeatedly at many different points to prevent there being any unscanned areas. Installation location points were accurately recorded on a worksheet when targets were used for joining points and checkpoints.

As the digital inventory of important properties required not only accurate records on the state of a target cultural property, but also a detailed work procedure for acquiring high-quality digital data, a detailed scan was carried out taking account of the wind velocity and the height of a cultural property during the survey process.

The prime consideration during the writing of scanning guides and carrying out of work at the actual site was the writing of detailed records about the inventory procedure. In the past, after digital inventory work using 3D laser scanning, only the data existed without any detailed records about the working environment and work outcome. Therefore, the quality of the data could not be assured, and in most cases the level of utilization was very low. Therefore, worksheets have been filled in thoroughly in the recent digital inventory procedure as shown below, to enable the work procedure, working environment, work details, and other information to be checked in detail. The information in the data outputs was preserved, so it could be useful if the data needed to be used in the future. The contents of the worksheets consist of the type, size, conditions of carving, accessibility, scanning methods, names of scanning equipment, and other information of a target cultural property. Also scan position information was marked on a map on worksheets, to be helpful if the data needed to be used in the future.

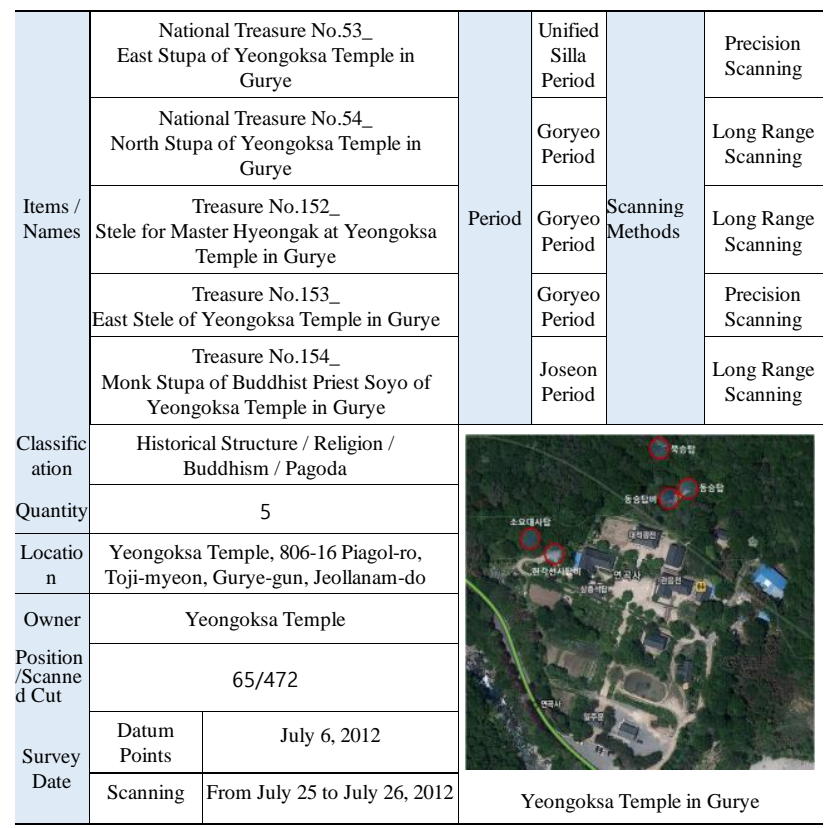




\begin{tabular}{|c|c|c|c|c|c|c|}
\hline & \begin{tabular}{c|} 
National \\
Treasure No.53
\end{tabular} & $\begin{array}{l}\text { Treasure } \\
\text { No.153 }\end{array}$ & $\begin{array}{c}\text { National } \\
\text { Treasure } \\
\text { No.54 }\end{array}$ & $\begin{array}{l}\text { Treasure } \\
\text { No.152 }\end{array}$ & $\begin{array}{l}\text { Treasure } \\
\text { No.154 }\end{array}$ & $\begin{array}{c}\text { Entire Area } \\
\text { Temple }\end{array}$ \\
\hline Type & \multicolumn{6}{|c|}{ Fixed Type (Immovable Cultural Properties) } \\
\hline $\begin{array}{c}\text { Size } \\
\text { (small/medium } \\
\text { /large) }\end{array}$ & \multicolumn{6}{|c|}{ Large } \\
\hline $\begin{array}{l}\text { Patterns and } \\
\text { Inscriptions }\end{array}$ & \multicolumn{5}{|c|}{ Elaborated } & N/A \\
\hline Accessibility & \multicolumn{6}{|c|}{ Good } \\
\hline $\begin{array}{l}\text { Scanning } \\
\text { Methods }\end{array}$ & $\begin{array}{r}\text { Precision Scann } \\
\text { Range Scar }\end{array}$ & $\begin{array}{l}\text { ing + Long } \\
\text { nning }\end{array}$ & \multicolumn{4}{|c|}{ Long Range Scanning } \\
\hline $\begin{array}{c}\text { Survey } \\
\text { Equipment }\end{array}$ & \multicolumn{2}{|c|}{ ATOS + C10 } & \multicolumn{4}{|c|}{ C10 } \\
\hline Cut / Position & & & \multicolumn{4}{|c|}{$\begin{array}{l}3 \text { cuts / A total of } 96 \text { positions for the long range } \\
\text { scanning in the entire area of } \\
\text { Yeongoksa Temple, a total of } 66 \text { positions } \\
\text { for the mapping photographs }\end{array}$} \\
\hline Photograhs & 221 & 213 & 94 & 151 & 169 & $\cdot$ \\
\hline Remarks & & & & & & \\
\hline
\end{tabular}

\begin{tabular}{|c|c|c|}
\hline & Name of Product & Purpose of Usage \\
\hline \multirow{5}{*}{$\mathrm{H} / \mathrm{W}$} & Leica ScanStation C10 & 3D Long Range Scanning \\
\hline & $\begin{array}{l}\text { ATOS Compact Scan } 2 \mathrm{M} \\
\text { Lens: } 300 \mathrm{x} 600\end{array}$ & 3D Precision Scanning \\
\hline & $\begin{array}{c}\text { TriMBle } 5700 \\
\text { Antenna: Zephyr }\end{array}$ & Datum Point Measurement \\
\hline & $\begin{array}{c}\text { Canon 5D Mark II } \\
\text { Lens: Conon EF 24-70mm F2.8L USM }\end{array}$ & Basic Image Photography \\
\hline & $\begin{array}{c}\text { Nikon D200 } \\
\text { Lens: Sigma 8mm F3.5 EX DG Circular Fisheye }\end{array}$ & $\begin{array}{c}\text { Mapping Color Source \& } \\
\text { Panoramic Image Photography }\end{array}$ \\
\hline
\end{tabular}
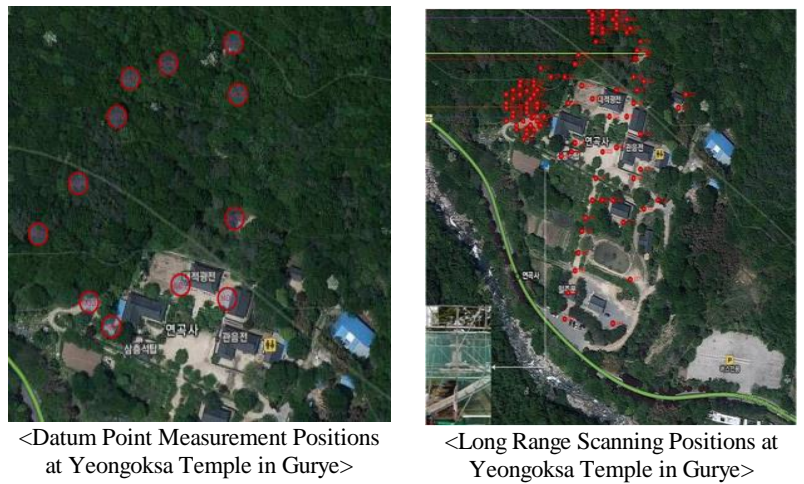

The final work procedure for the main survey is photographing the mapping source, which is required to obtain the RGB color information for the point cloud data acquired by long range scanning. It is a rule to place a target object on a horizontal line, and photograph in an environment where there is no shadow if possible. Also, the photographing process involves taking photographs with grey cards and color cards for color correction later.

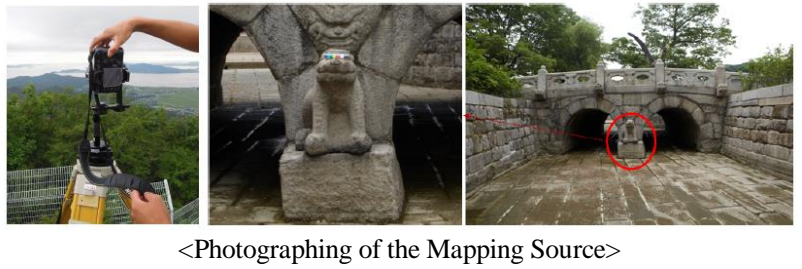

Once the main survey is completed with photographing mapping sources, the post-processing and mapping of data acquired at the site are carried out. First, the original data obtained at the site is saved unchanged, and the postprocessing step is carried out using copies of this data. The post-processing steps consist largely of matching, removing noise, and mapping. If the datum points have been measured, a process of datum point data entry is added after the matching process. The details are explained below.

\section{a. Registration}

Matching refers to integrating several cuts of data acquired from the 3D long range scans by overlapping on the basis of the same point. From this process, one featuring data is created. Matching is divided into automatic and manual matching. Each precision scanned shell data arranged by the manual aligning process is accurately calculated with a permissible range such as allowable error, the calculated number of point clouds,' and the number of repetitions, and then the merged 3D precision scanning data is produced with minimum error. If the range of allowable error is not satisfactory, the precision matching process is carried out again.

\section{b. Noise removal}

When scanning a site, sometimes point cloud data which is unrelated to the target cultural property is acquired due to people or moving objects, and this is called noise. When noise is found, it should be removed either automatically or manually, confirming it through the naked eye.

If the digital inventory work is carried out by long range scanning on immovable cultural properties, datum point data is entered after post-processing. Entering datum point data, also called geocoding, is a process where the coordinates acquired by measuring datum points are entered into the long range scanned data. Through this process, the scanned data has location information on the earth's surface. Therefore, in the case of long range scanning in which datum points are measured, the scanned data where datum point data has been entered is the final product.

\section{c. Mapping}

Mapping is the final step of the inventory process using 3D laser scanning. It is to overlay the $2 \mathrm{D}$ photographic data into the 3D scanned data. In other words, the color values are given by overlaying the mapping sources which were separately taken at the site into the point cloud data acquired by long range scanners. The purpose of this process is to construct 3D scanned data which is close to the actual color. This is the final step of the post-processing. 


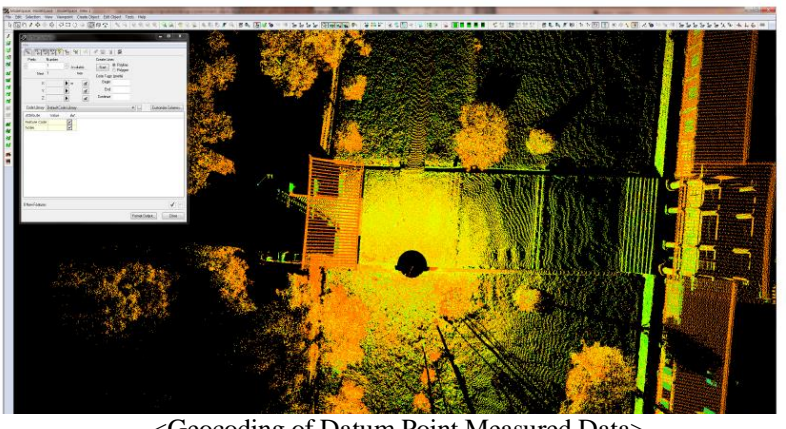

$<$ Geocoding of Datum Point Measured Data $>$
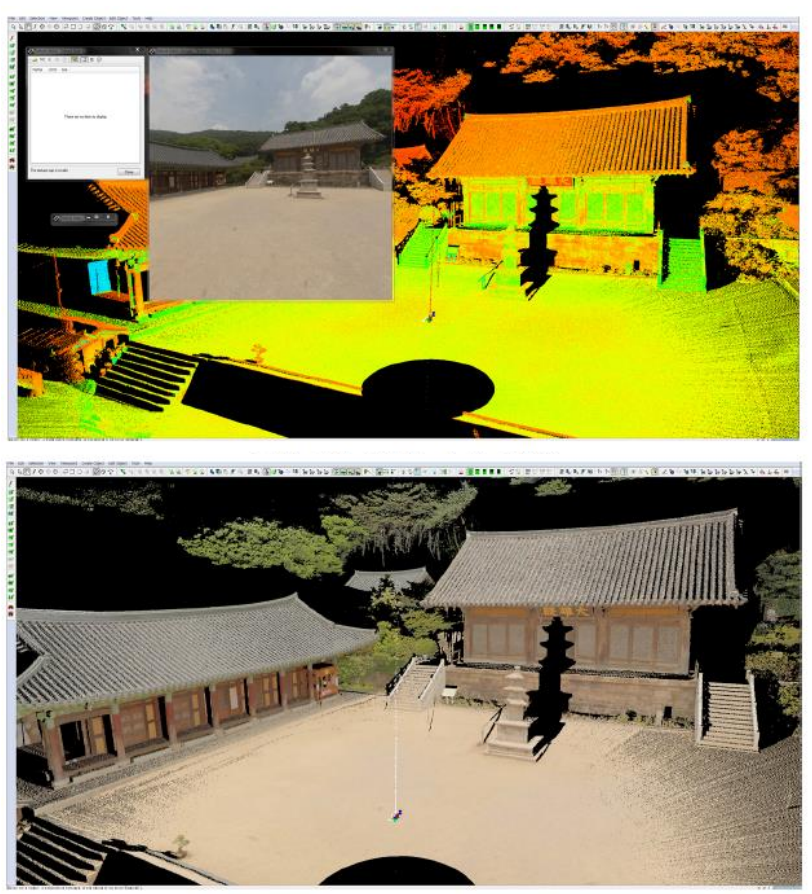

<Standardization of the Mapping Process of Post-processing Data>

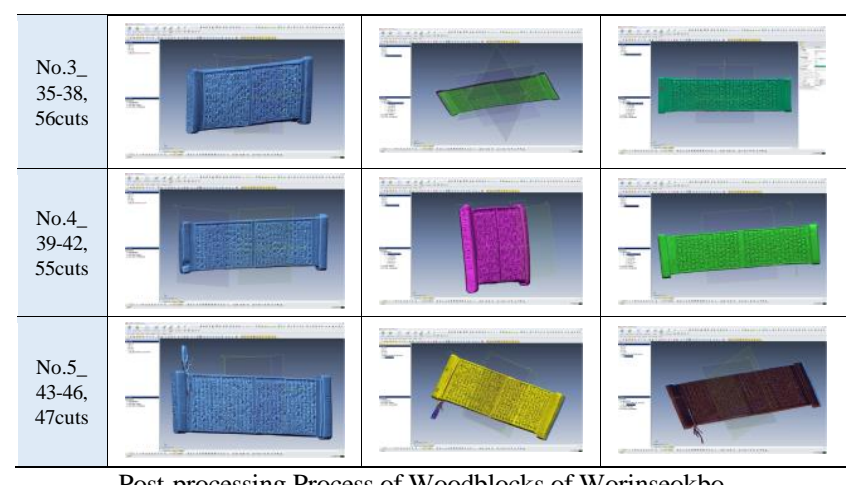

ost-processing Process of Woodblocks of Worinseokbo (From left, matching, modeling, and mapping)

\begin{tabular}{|c|c|c|c|c|c|}
\hline PROCESS & \begin{tabular}{|c|} 
ITEMS TO BE \\
CHECKED
\end{tabular} & $\begin{array}{l}\text { NO.3- } \\
35-38 \\
\end{array}$ & $\begin{array}{l}\text { NO.4- } \\
39-42 \\
\end{array}$ & $\begin{array}{l}\text { NO.5- } \\
43-46 \\
\end{array}$ & sw \\
\hline IMPORT & \begin{tabular}{|c|} 
Original files \\
(Converted to ASC \\
format)
\end{tabular} & 56 cuts & 55 cuts & 47 cuts & $\begin{array}{l}\text { Rapidform, } \\
\text { Cyclone }\end{array}$ \\
\hline $\begin{array}{c}\text { DATA } \\
\text { VERIFICATIO } \\
\mathbf{N}\end{array}$ & $\begin{array}{c}\text { Degree of precision } \\
\text { verified }\end{array}$ & Below $3 \mathrm{~mm}(1 \mathrm{~mm})$ & Below $3 \mathrm{~mm}(1 \mathrm{~mm})$ & Below $3 \mathrm{~mm}(1 \mathrm{~mm})$ & $\begin{array}{c}\text { Rapidform, } \\
\text { Cyclone }\end{array}$ \\
\hline MATCHING & Error range verified & $\begin{array}{l}\text { Verified with the } \\
\text { naked eye }\end{array}$ & $\begin{array}{l}\text { Verified with the } \\
\text { naked eye }\end{array}$ & $\begin{array}{l}\text { Verified with the } \\
\text { naked eye }\end{array}$ & $\begin{array}{c}\text { Rapidform, } \\
\text { Cyclone }\end{array}$ \\
\hline MERGER & $\begin{array}{l}\text { Degree of precision } \\
\text { verified }\end{array}$ & Below $3 \mathrm{~mm}(1 \mathrm{~mm})$ & Below $3 \mathrm{~mm}(1 \mathrm{~mm})$ & Below $3 \mathrm{~mm}(1 \mathrm{~mm})$ & \begin{tabular}{|c|} 
Rapidform, \\
Cyclone
\end{tabular} \\
\hline MODELING & $\begin{array}{l}\text { Modeled under the } \\
\text { approval of the } \\
\text { person in charge. }\end{array}$ & $\begin{array}{c}\text { Verification } \\
\text { completed after } \\
\text { capturing data and } \\
\text { delivering images }\end{array}$ & \begin{tabular}{|c|} 
Verification \\
completed after \\
capturing data and \\
delivering images
\end{tabular} & \begin{tabular}{|c|} 
Verification \\
completed after \\
capturing data and \\
delivering images
\end{tabular} & $\begin{array}{c}\text { Cyedit } \\
\text { (Headus) }\end{array}$ \\
\hline MAPPING & $\begin{array}{l}\text { Outdoor / Indoor } \\
\text { (Photographing) }\end{array}$ & Indoor & Indoor & Indoor & $\begin{array}{l}\text { Cyedit } \\
\text { (Headus)/ } \\
\text { Photoshop }\end{array}$ \\
\hline
\end{tabular}

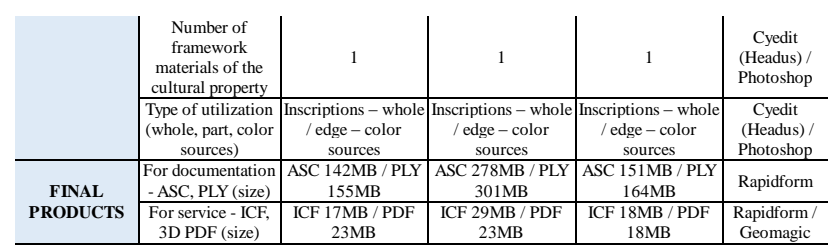

$<$ Post-processing and a Worksheet for the Precision Scan Data of an Important Movable Cultural Property>

Mainly the inventory work done using long range scanning has been explained so far. The precision scanning work procedure on small important movable cultural properties is almost the same. There were many problems with data management and utilization because no detailed records on the work procedure remained after precision scanning took place. Therefore, these problems have been supplemented by the filling in of separate worksheets. The worksheets contain detailed information about the degree of data precision, as well as the error range, information on modeling and mapping, software used for the work process, and final products.

5.2 Standardization of quality and management of digital inventory data

\section{a. Data quality test}

For the inventory process using 3D laser scanning, the onsite survey is important. However, the inspection procedure on the data that has been through post-processing is also important, to ensure the quality of the inventoried data. People who carried out the project performed their own inspections of the 3D scanned data at the stages of data construction and postprocessing completion. Detailed information was recorded on each worksheet, and inspectors who had expert knowledge inspected the records. During the inspection process, each data inspection sheet about each object and scanning method was filled in by referring to the already-filled in worksheets about each survey.

The inspection sheets for the long range scanning included the point density levels of the original data and integrated data, whether noise removal from the mapping source was performed, whether measurement of datum points was carried out, and whether the temporary coordinates were entered. In addition, the size and drawing composition of the original scanned data and post-processed data, number of frames, running time, and file formats of videos were checked. Moreover, software used during the inspection process was required to be recorded, to enable the quality of the data to be secured.

\begin{tabular}{|c|c|c|c|c|c|}
\hline \multicolumn{6}{|c|}{ Delivery Sheet for Long Range Scan Data } \\
\hline \multirow{2}{*}{$\begin{array}{l}\text { Name of the } \\
\text { Cultural } \\
\text { Property }\end{array}$} & & & & Date & \\
\hline & & & & $\begin{array}{c}\text { Project } \\
\text { Manager }\end{array}$ & \\
\hline Process & \multicolumn{3}{|c|}{ Items To Be Checked } & SW & Remarks \\
\hline Original Scan Data & \multicolumn{2}{|c|}{$\begin{array}{l}\text { Point Density Check } \\
\text { (Cultural Property) }\end{array}$} & & & \\
\hline Merged Scan Data & \multicolumn{2}{|c|}{$\begin{array}{c}\text { Point Density Check } \\
\text { (Cultural Property) }\end{array}$} & & & \\
\hline Mapping & \multicolumn{2}{|c|}{ Mapping Noise } & Yes / No & & \\
\hline \multirow{2}{*}{$\begin{array}{l}\text { Georeferencing } \\
\text { of Datum Point }\end{array}$} & \multicolumn{2}{|c|}{ Public Surveying Assessment } & Yes / No & & \\
\hline & \multicolumn{2}{|c|}{ Using Arbitrary Coordinates } & Yes / No & & \\
\hline \multirow{3}{*}{$\begin{array}{c}\text { Final } \\
\text { Deliverables }\end{array}$} & \multirow{2}{*}{$\begin{array}{c}\text { Data for } \\
\text { Documentation }\end{array}$} & Original & $\begin{array}{ll}\text { Raw( } & \text { MB), } \\
\text { ASC( } & \text { MB) } \\
\end{array}$ & - & \\
\hline & & Post-processed & $\operatorname{ASC}(\mathrm{MB})$ & & \\
\hline & \multicolumn{2}{|c|}{ Drawings } & $\begin{array}{c}\text { Contents of drawings / } \\
\text { scales }\end{array}$ & & \\
\hline
\end{tabular}




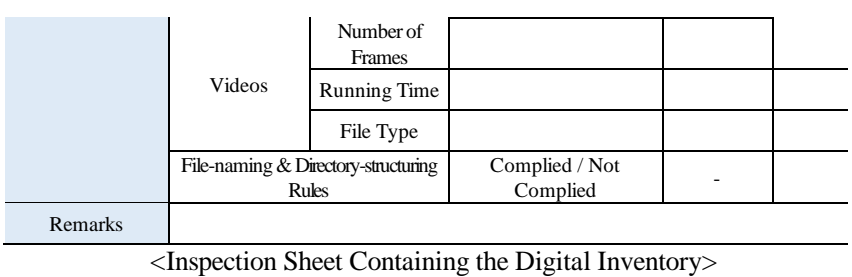

For the precision scanning inspection sheets, the information on the point density of original data and whether any unscanned areas exist is checked, and for the modeling data, the format, size, and the number of polygons are required to be checked and recorded. Moreover, the type of mapping sources, the size and drawing content composition of original data and post-processed data, composition, file naming, and directory structure of additional outputs should also be checked as to whether they have been completed in compliance with the guidelines. Software used during the inspection process is recorded on the precision scanning inspection sheets.

\section{b. Management of inventoried data}

After the completion of the acquisition and inspection of digital data on important cultural properties using 3D laser scanning, as the final step for the inventory, the composition of data and file formats were standardized by dividing them into data for preservation for the management of archetypical information and data for web services which can be utilized internally and externally.

The data created by the digital inventory work was composed in compliance with the 'Standard Data Production Instructions for the Documentation Project for Cultural Properties' by the Cultural Heritage Administration. Taking the conservation of the archetypes of cultural properties and the increase in the utilization of data into consideration, which was the purpose of the digital inventory project, file formats were divided into file formats for preservation and for web services. File formats followed international standards. However, if there were no international standards, the most widely used file formats were used. While defining file formats, the following rules have been set out to increase the management efficiency and utilization of data in the future. First, files for preservation must be the original files for those files used for web services, uncompressed, and contain all the original information of the target cultural properties. Second, the files for web services must have multi-usability and compatibility, and the size and formats of these files must be suitable for the web service environment. The data types and file formats composed according to the rules above are as follows.

\begin{tabular}{c|c|l|c}
\hline $\begin{array}{c}\text { Type of } \\
\text { Data }\end{array}$ & File Format & \multicolumn{1}{|c|}{ File Description } & $\begin{array}{c}\text { Standard or } \\
\text { Non-standard }\end{array}$ \\
\hline \multirow{2}{*}{$\begin{array}{c}\text { 3D Scan } \\
\text { Data }\end{array}$} & Original Files & $\begin{array}{l}\text { The first data which is stored in a scanner after 3D } \\
\text { scanning. File format would vary depending on the } \\
\text { type of the scanner. }\end{array}$ & $\begin{array}{c}\text { Non- } \\
\text { standard }\end{array}$ \\
\cline { 2 - 4 } & ASC & $\begin{array}{l}\text { ASC files are text-only files and files written in ASCII } \\
\text { Code. They are also called text files, text-only files, or } \\
\text { ASC text files. Here, it refers to the files generated by } \\
\text { the ASC II code. }\end{array}$ & $\begin{array}{c}\text { Non- } \\
\text { standard }\end{array}$ \\
\hline 2D Images & Original Files & $\begin{array}{l}\text { PLY files are 3D modeling files generated through } \\
\text { meshing. }\end{array}$ & $\begin{array}{c}\text { Non- } \\
\text { standard }\end{array}$ \\
\hline images. & $\begin{array}{c}\text { Non- } \\
\text { standard }\end{array}$ \\
\hline
\end{tabular}

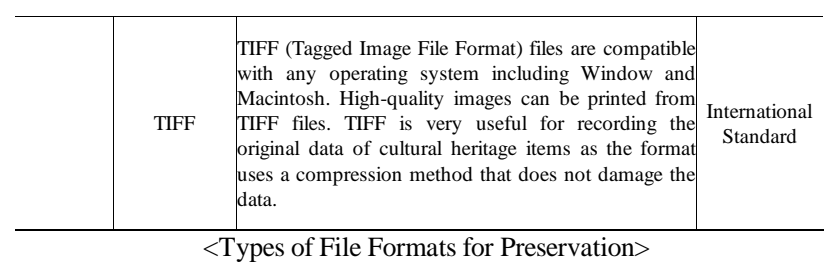

\begin{tabular}{|c|c|c|c|}
\hline $\begin{array}{c}\text { Type of } \\
\text { Data }\end{array}$ & File Format & File Description & $\begin{array}{c}\text { Standard or } \\
\text { Non-standard }\end{array}$ \\
\hline \multirow{3}{*}{$\begin{array}{l}\text { 3D Scan } \\
\text { Data }\end{array}$} & WRL & $\begin{array}{l}\text { VRML (virtual reality modeling language) is a text file } \\
\text { format for displaying 3D space on the web which uses } \\
\text { the filename extension of wrl. VRML files can only be } \\
\text { displayed on a browser exclusively made for VRML. }\end{array}$ & $\begin{array}{l}\text { International } \\
\text { Standard }\end{array}$ \\
\hline & $\mathrm{X} 3 \mathrm{D}$ & $\begin{array}{l}\text { As the name implies, X3D is a file format for } \\
\text { representing 3D graphics and has more extended } \\
\text { functions compared to VRML. } \\
\text { X3D is extensible 3D graphics. The name X3D refers } \\
\text { to its integration with XML. X3D is completely } \\
\text { compatible with VRML and has all the functions of } \\
\text { VRML. VRML formats are convertible into X3D } \\
\text { formats through using stylesheet. }\end{array}$ & $\begin{array}{l}\text { International } \\
\text { Standard } \\
\end{array}$ \\
\hline & ICF & ICF is a file extension for viewing $3 \mathrm{D}$ information. & Non-standard \\
\hline $\begin{array}{c}2 \mathrm{D} \\
\text { Images }\end{array}$ & JPG & $\begin{array}{l}\text { JPG provides maximum compression rates of } 20: 1 \text { of } \\
\text { images and supports true } 24-\text {-bit color. It is a file format } \\
\text { that is commonly used not only on the Internet but } \\
\text { also in multimedia environments. Advantages of this } \\
\text { file format are that it offers a smaller file size, but has } \\
\text { relatively high efficiency on the quality loss of images } \\
\text { compared to other file formats. }\end{array}$ & $\begin{array}{c}\text { International } \\
\text { Standard } \\
\end{array}$ \\
\hline
\end{tabular}

In the case of producing drawings, photographs, videos, and 3D PDF files created during the digital inventory process using 3D laser scanning, the production standards and file formats of each final product were designated to increase the efficiency of the data utilization. The types of drawings were divided into point cloud images and line drawings. In this case, they are basically composed of the front, rear, plane and cross-sectional elevation. Videos were produced using camera animation mainly on the 3D long range scanned data (point cloud data). Camera animation was selected in consideration of the size and characteristics of the target cultural property, and the videos were produced in consideration of the resolution, video play time, and visual media which will play the video. 3D PDF files were produced to be easily opened with general PDF programs. As 3D PDF files have a characteristic of giving easy access to cross sections of a cultural property that a user wants to have, the file size should be less than 100MB to help general users to open the files easily.

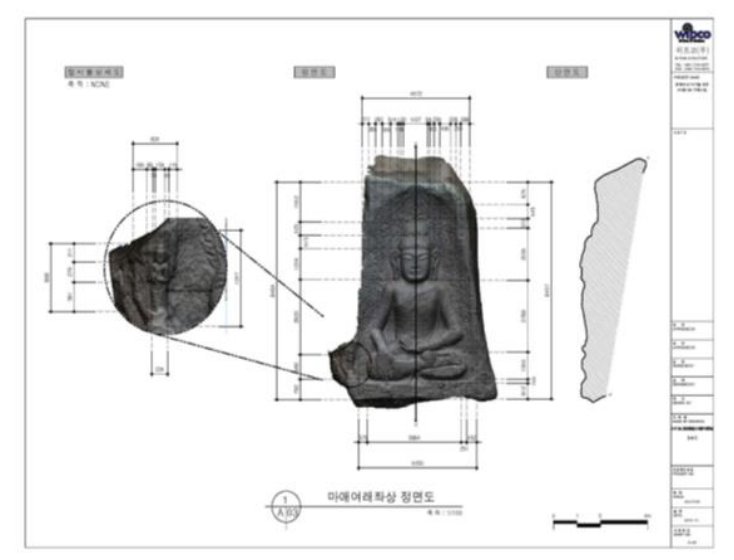




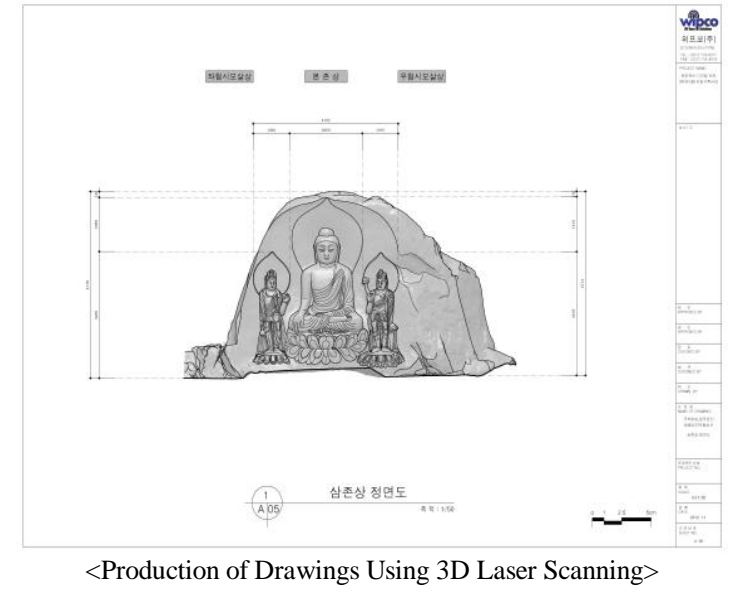

As stated above, the guidelines have been proposed for the data acquired from digital inventory using 3D laser scanning to be produced and managed through the standardization of quality testing, data formats, and the composition of data. The final products from the digital inventory have been standardized as per the table below, to assist in the management and utilization of the inventoried data using 3D laser scanning in the future.

\begin{tabular}{|c|c|c|c|}
\hline Type & Subtype & $\begin{array}{c}\text { Files for } \\
\text { Documentation }\end{array}$ & $\begin{array}{l}\text { Files for Web } \\
\text { Services }\end{array}$ \\
\hline \multirow[b]{2}{*}{ 3D Scan Data } & Long Range Scan Data & Original Files, ASC & - \\
\hline & Precision Scan Data & $\begin{array}{c}\text { Original Files, ASC, } \\
\text { PLY }\end{array}$ & $\begin{array}{c}\text { WRL, X3D, ICF, } \\
\text { PDF }\end{array}$ \\
\hline \multirow[t]{2}{*}{ Images } & Mapping Source & Original Files, TIFF & $\begin{array}{l}\text { JPG (72 pixels } \\
300 \text { pixels })\end{array}$ \\
\hline & Photographs & Original Files, TIFF & JPG (300 pixels) \\
\hline \multirow{3}{*}{ Drawings } & $\begin{array}{l}\text { Drawings of the Surroundings of } \\
\text { Cultural Properties }\end{array}$ & DWG & DWF, JPG \\
\hline & Scan Data Image Drawing & DWG & DWF, JPG \\
\hline & Line-drawings & DWG & DWF, JPG \\
\hline Multimedia & Videos & Original AVI & $\begin{array}{l}\text { MPEG2, WMV, } \\
\text { MP4, ASF }\end{array}$ \\
\hline \multirow{4}{*}{ Worksheet } & Long Range Scanning & \multirow{4}{*}{ HWP } & \multirow{4}{*}{ - } \\
\hline & Precision Scanning & & \\
\hline & Measurement of Data Point & & \\
\hline & Photography & & \\
\hline \multirow{2}{*}{$\begin{array}{l}\text { Inspection Sheet for } \\
\text { Scan Data }\end{array}$} & Long Range Scanning & \multirow{2}{*}{ HWP } & \multirow{2}{*}{ - } \\
\hline & Precision Scanning & & \\
\hline \multirow{2}{*}{$\begin{array}{l}\text { Measurement of } \\
\text { Datum Point }\end{array}$} & Report of Datum Point & HWP & - \\
\hline & $\begin{array}{c}\text { Evaluation Report of Public } \\
\text { Survey }\end{array}$ & PDF & - \\
\hline
\end{tabular}

<Composition list of laser scanning digital data and definitions of file formats〉

At present, the data established through digital inventory and documentation projects of important cultural properties are managed by the systematically composed directory as below. The actual data is collectively managed by the cultural property archetypical information system, which operates within the Cultural Heritage Administration. Moreover, the outcome of the digital inventory projects is available to the public via the digital hub of Korea National Heritage Online, serviced by the Cultural Heritage Administration, which increases the utilization of the data.

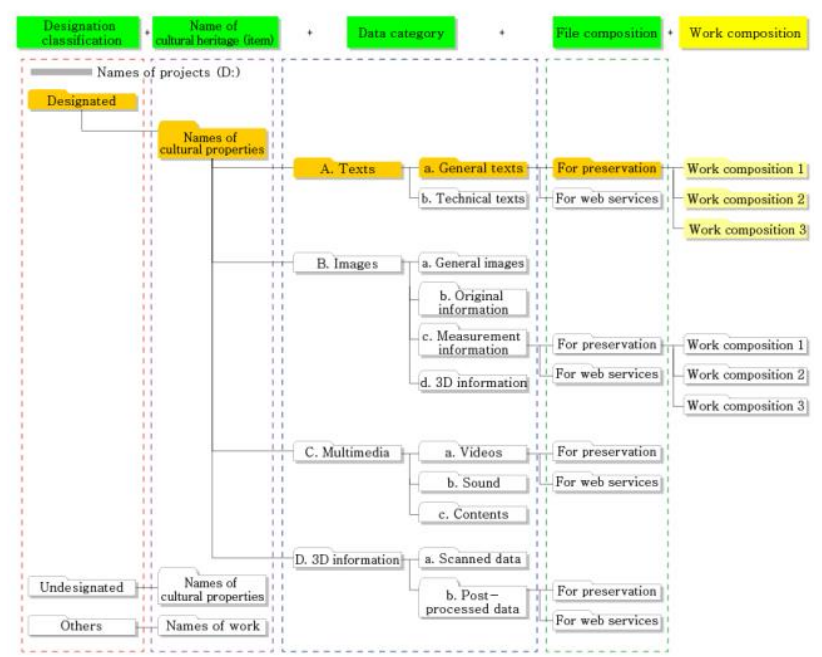

$<$ Directory Diagram for the Digital Inventoried Data of Important Cultural Properties>

\section{CONCLUSION}

Korea has been continuously carrying out the inventory and documentation of cultural properties since the 1960s. However, recently the need for securing, managing, and utilizing digital resources was raised. To carry out this inventory and documentation more effectively, integrated management and a utilization plan for digital resources have been prepared. In this process, the concept of 'a digital set' was introduced to increase the degree of completeness of the digital inventory projects of the important cultural properties. Moreover, the system was organized systematically to collectively manage and utilize digital data through business process reengineering in the Cultural Heritage Administration. Guidelines to standardize the laser scanning work, secure the high quality data, and standardize the data management, which forms a large part of the inventory of important cultural properties, have also been created.

The series of process and outcome have greatly contributed to the inventory and documentation of cultural properties as they have overcome the limitations of the previous analog method inventory and documentation of important cultural properties, and have enabled the acquisition and management of high quality archetypical information in case of damage to and for the restoration of cultural properties and the production and utilization of its contents.

\section{REFERENCES}

Cultural Heritage Administration, 2007. Guidebook for recording project Cultural Heritage, Deajeon, Korea.

Cultural Heritage Administration, 2011. Establish an ISP(Infromation strategies Plan) for cultural heritage information recorded Data, Deajeon, Korea.

Cultural Heritage Administration, 2012. Study on Integrated Management Plan for the promotion and utilization of cultural heritage recording information, Deajeon, Korea.

Cultural Heritage Administration, 2013. A Guide of 3D Laser Scanning for Cultural Properties, Deajeon, Korea. 